more classes. A significant increase in risk of endometrial cancer is found for relatedness when all the relatives are taken together but not for each type of relative. The same applies to risk of prostate cancer according to cancer in first degree relatives of the probands. When second degree and more distant relatives are divided into five classes according to whether the proband had first degree relatives with prostate, breast, ovarian, or endometrial cancer or none, the only significant increase in risk was for prostate cancer. When the categories considered were restricted to prostate cancer, breast cancer, and neither, a significantly increased risk of breast cancer was also found.

Body mass has been suggested as a confounding factor. Body mass index has been reported to be a risk factor for breast cancer ${ }^{14}$ or prostate cancer. ${ }^{15}$ But in Icelandic cohort studies it was not found a significant risk factor for any of the cancer sites considered in this study. ${ }^{1617}$ For breast cancer, however, both height and weight independently were positive risk factors, as were body surface and lean body mass. General lifestyle factors may affect husband and wife in a similar way. We therefore tested whether the husbands of the probands had an increased risk of prostate cancer when compared with husbands of female relatives. No indication of increased risk. in husbands of probands was found.

The results suggest that the familiality of breast cancer is heterogeneous in that the increase in risk of breast and prostate cancer in relatives of probands is not confined to first degree relatives, as it is among endometrial and ovarian cancer. The power of this study to show an increased risk among second degree relatives is considerably stronger for prostate cancer than for ovarian cancer.

We thank the genetics committee of the University of Iceland, which developed the system allowing construction of pedigrees of Icelanders. This has provided most of the information necessary for the family trees reported on in this publication. This study was supported by the research fund of the Icelandic Cancer Society.

1 Tulinius H, Sigvaldason H, Olafsdóttir G, Tryggvadóttir L. Epidemiology of breast cancer in families in Iceland. $\mathcal{F}$ Med Genet 1992;29:158-64.

2 Statistics and Epidemiology Research Corporation. EGRET reference manual. Seattle: SERC, 1990

3 Thiessen EU. Concerning a familial association between breast cancer and both prostatic and uterine malignancies. Cancer 1974;34:1102-7.

4 Cannon L, Bishop D, Skolnick M, Hunt S, Lyon JL, Smart CR. Genetic epidemiology of prostate cancer in the Utah Mormon genealogy. Cancer Surveys 1982:1:47-69.

5 Lynch HT, Harris RE, Guirgis HA, Maloney K, Carmody LL, Lynch JF. Familial association of breast/ovarian carcinoma. Cancer 1978;41:1543-9.

6 Lynch HT, Albano WA, Lynch JE, Lynch PM, Campbell A. Surveillance and management of patients of high genetic risk for ovarian carcinoma. Obstet Gynecol 1982;59:589-96.

7 King MC, Go RCP, Elston RC, Lynch HT, Petrakis NL. Allele increasing susceptibility to human breast cancer may be linked to the glutamatepyruvate transaminase locus. Science 1980;208:406-8.

8 Williams WR, Anderson DE. Genetic epidemiology of breast cancer: $\vec{O}$ segregation analysis of 200 Danish pedigrees. Genet Epidemiol 1984;1:7-20.

9 Ferrell RE, Anderson DE, Chidambaram A, Marino TR, Badzioch M. A genetic linkage study of familial breast-ovarian cancer. Cancer Genet $\omega$ Cytogenet 1989;38:241-8.

10 Schildkraut JM, Risch N, Thompson WD. Evaluating genetic association among ovarian, breast and endometrial cancer: evidence for a breast/ovarian cancer relationship. Am 7 Hum Genet 1989;45:521-9.

11 Thompson WD, Schildkraut JM. Family history of gynecological cancers: relationships to the incidence of breast cancer prior to age 55. Int $\gamma$ Epidemi 1991:20:595-602.

12 Hall JM, Lee MK, Newman B, Morrow JE, Anderson LA, Huey B, et al. O Linkage of early-onset familial breast cancer to chromosome 17q21. Science 1985;250:1684-9.

13 Narod SA, Feunteun J, Lynch HT, Watson P, Conway T, Lynch J, et al. Gु Familial breast-ovarian cancer locus on chromosome 17q12-q23. Lancet 1991;338:82-3

14 Vatten LJ, Kvinnsland S. Body mass index and risk of breast cancer. A prospective study of 23,826 Norwegian women. Int $\mathcal{C}$ Cancer 1990;45:440-4.

15 Nomura AMY, Kolonel LN. Prostate cancer: a current perspective. Epidemiologic Reviews 1991;13:200-27.

16 Tulinius H, Sigfússon N, Sigvaldason H, Day NE. Can anthropometric and biochemical measurements illustrate the diet-cancer connection? Näringsforskning 1985;29:17-22.

17 Tulinius H, Sigfússon N, Sigvaldason H, Day NE. Relative weight and human cancer risk. In: Joosens JV, Hill MJ, Gebors J, eds. Diet and human 21st Gum 1985, Ams Congress Series No 685 .)

(Accepted 20 August 1992)

\title{
Epilepsy in the first 10 years of life: findings of the child health and education study
}

\author{
C M Verity, E M Ross, Jean Golding
}

\section{Abstract}

Objectives-To identify children with afebrile seizures in a national cohort, classify the seizures, and document progress in the first 10 years of life.

Design-Population based birth cohort study.

Setting-The child health and education study, which includes 16004 neonatal survivors $(98 \cdot 5 \%$ of infants born in the United Kingdom during one week of April 1970).

Subjects-14676 children for whom relevant information was available.

Main outcome measures-Responses to parental and general practitioner questionnaires and hospital records at 5 and 10 years after birth.

Results -84 children ( 42 boys, 42 girls) had had one or more afebrile seizure (incidence 5·7/1000). 63 children ( 31 boys, 32 girls) had epilepsy (incidence 4.3/1000). 49 of 55 children had a second seizure within a year of the first. The commonest seizure types were tonic-clonic (42) and complex partial (25). A greater proportion of children with complex partial seizures had recurrences. Children who had infantile spasms or a mixed seizure disorder had a poor outcome. All six children who died had symptomatic seizures in the first year, but seizures were not the direct cause of death.
Conclusions-The results of this study are probably representative of seizure patterns in the general population. Outcome after seizures is determined more by the underlying disease than by the seizures themselves.

\section{Introduction}

The child health and education study has prospectively followed a cohort of 16004 neonatal survivors born in one week in April 1970. Detailed clinical information was obtained about children suspected of having seizures. Only a few studies have been large $\stackrel{\oplus}{\oplus}$ enough to obtain similar data about seizure disorders in childhood. ${ }^{1-4}$ This paper reports on the study children who had had one or more afebrile seizures by 10 years of age.

\section{Subjects and methods}

The child health and education study started as the 1970 British births survey. ${ }^{5}$ This survey enrolled $98.5 \%$ of the infants born in the United Kingdom in one week in April 1970; 13135 (82\%) of the survivors were assessed at 5 years of age and $14902(93 \%)$ at 10 years. As part of both assessments the parents were 
asked "Has the child ever had any form of convulsion, seizure or other turn in which consciousness was lost or any part of the body made an abnormal movement?" At the 10 year follow up replies to this question were available for 14676 children, 1318 of whom had had a suspicious event. Parents' responses were validated by sending a questionnaire to general practitioners at 5 and 10 years: general practitioners returned questionnaires for $92 \%$ of the children with suspected seizures and hospital records were obtained for $89 \%$ of the children seen in hospital. Hospital records of children who had died after the neonatal period were searched for evidence of afebrile seizures.

Eighty four children had had one or more afebrile seizures. Suspected seizures in the neonatal period (the first four weeks of life) were not included. A total of 398 children had had febrile convulsions, of whom 17 subsequently had afebrile seizures. ${ }^{0-8}$

In this part of the study children were classified as being developmentally delayed or having learning disabilities on the basis of clinical information in hospital notes and questionnaires and not by using standardised tests.

The box shows the definitions of seizures and epilepsy. Classification of afebrile seizures was based on the proposals of the International League Against Epilepsy, revised in $1981 . .^{\circ}$ We differed from these proposals in retaining "infantile spasms" and also in having a category of "mixed seizures" for children with more than one seizure type.

Proportions were compared by the $\chi^{2}$ test with Yates's correction. Fisher's exact test was used for numbers less than five.

\section{Results}

MANAGEMENT OF CHILDREN WITH SEIZURES

Eighty four children had had afebrile seizures, of whom 78 had attended hospital outpatients and 58 had been admitted to hospital. Thirty four children had had skull radiography, 30 lumbar puncture, six computed tomography, and 60 electroencephalography. Results of electroencephalography were available for 58 children and were normal in 19. Twenty eight of 42 children $(67 \%)$ with tonic-clonic seizures and 20 of 25 children $(80 \%)$ with complex partial seizures had had electroencephalography. Anticonvulsants had been prescribed for more than a month for six of 21 children $(29 \%)$ who had had only one seizure and 59 of 62 children $(95 \%)$ who had recurrent seizures.

\section{INCIDENCE OF AFEBRILE SEIZURES AND EPILEPSY}

By the age of 10 years 84 children ( 42 boys, 42 girls) had had one or more afebrile seizures. Data were available for 14676 children, giving an incidence of $5 \cdot 7 / 1000$. First seizures occurred at a median age of 3 years (range 5 weeks -9 years 3 months). Excluding the neonatal period, 23 seizures occurred in the first

TABLE I-Number of children with different seizure types

\begin{tabular}{lcc}
\hline & $\begin{array}{c}\geqslant 1 \text { Afebrile } \\
\text { seizures }\end{array}$ & Epilepsy \\
\hline Tonic-clonic & 42 & 24 \\
Complex partial & 25 & 22 \\
Mixed & 9 & 9 \\
Infantile spasms & 3 & 3 \\
Atypical absence & 2 & 2 \\
Absence & 1 & 1 \\
Myoclonic & 1 & 1 \\
Simple partial secondarily generalised & 1 & 1 \\
\hline Total & 84 & 63 \\
\hline
\end{tabular}

*All except four of the children with complex partial seizures had secondarily generalised attacks at some time.

\section{Definitions}

Afebrile seizure-“A paroxysmal disturbance of consciousness, sensation or movement, primarily cerebral in origin, unassociated with acute febrile episodes." We studied all children who had one or more afebrile seizures and used the term epilepsy for those with more than one afebrile seizure episode. Recurrent seizures during one 24 hour period were counted as a single episode

Status epilepticus-A seizure or series of seizures lasting more than 30 minutes

Remission of seizure- -2 or more years free of seizures before the 10 year follow up, whether or not anticonvulsant drugs were still prescribed

Active epilepsy-Afebrile seizures in the two years before the 10 year follow up in a child with epilepsy

Idiopathic seizures-Those for which there was no underlying diagnosis or history of neurological insult that could be considered a predisposing cause

Symptomatic seizures-Those that were not idiopathic.

TABLE II-Comparison of outcome in children with onset of seizures in the first year of life and those with later onset

\begin{tabular}{|c|c|c|c|}
\hline & $\begin{array}{l}\text { No }(\%) \text { with } \\
\text { onset in first } \\
\text { year }(n=23)\end{array}$ & $\begin{array}{l}\text { No (\%) with } \\
\text { onset after first } \\
\text { year }(n=61)\end{array}$ & $\begin{array}{c}\mathrm{p} \text { Value for } \\
\text { difference } \\
\text { between groups } \\
\left(\chi^{2} \text { value }\right)\end{array}$ \\
\hline $\begin{array}{l}\text { Symptomatic } \\
\text { Developmental delav or }\end{array}$ & $16(70)$ & $8(13)$ & $<0.0001(23.4)$ \\
\hline learning disability & $12 / 21(57)^{\star}$ & $13(21)$ & $<0.01(7.8)$ \\
\hline Status epilepticus & $4(17)$ & $14(23)$ & NS \\
\hline Recurrence (epilepsy) & $17 / 21(81)^{\star}$ & $46(75)$ & NS \\
\hline Remission after epilepsy & $5 / 13(38) \dagger$ & $17 / 46(37)$ & NS \\
\hline
\end{tabular}

^Excludes two children who died aged $<1$ year.

tExcludes six children who died as remission was defined as being seizure free at 10 years of age.

TABLE III-Comparison of children with symptomatic and idiopathic seizures

\begin{tabular}{|c|c|c|c|}
\hline & $\begin{array}{l}\text { No (\%) with } \\
\text { symptomatic } \\
\text { seizures } \\
(\mathrm{n}=24)\end{array}$ & $\begin{array}{l}\text { No (\%) with } \\
\text { idiopathic } \\
\text { seizures } \\
(n=60)\end{array}$ & $\begin{array}{c}\mathrm{p} \text { Value for } \\
\text { difference } \\
\text { between groups } \\
\left(\chi^{2} \text { value }\right)\end{array}$ \\
\hline $\begin{array}{l}\text { Developmental delay or } \\
\text { learning disability }\end{array}$ & $16 / 22(73) \dagger$ & $9(15)$ & $<0.0001(22.7)$ \\
\hline Onset $<1$ year & $16(67)$ & $7(12)$ & $<0.0001(23.4)$ \\
\hline Status epilepticus & $8(33)$ & $10(17)$ & NS \\
\hline Recurrence (epilepsy) & $19 / 22(86) \dagger$ & $44(73)$ & NS \\
\hline Remission after epilepsy & $3 / 15(20) \neq$ & $19 / 44(43)$ & NS \\
\hline
\end{tabular}

* Symptomatic seizures were due to cerebral palsy (four children) encephalitis (three), Rett syndrome (two), tuberous sclerosis (two), head injury (two), plus single cases of birth asphyxia, cerebral oedema and sepsis, collagenosis, hypernatraemic dehydration, hyperpyrexia (hot bath when febrile), intracranial haemorrhage, Leigh's encephalopathy, meningitis (Salmonella typhimurium), postoperative complications (Ramstedt), shunt for hydrocephalus, and Sturge-Weber syndrome.

†Excludes two children who died aged $<1$ year.

$\ddagger$ Excludes six children who died as remission was defined as being seizure free at 10 years of age.

year $(1 \cdot 6 / 1000 /$ year $), 12$ in the second year $(0 \cdot 8 / 1000 /$ year), and 11 in the third year $(0 \cdot 7 / 1000 /$ year). After that the rate became fairly constant at about six per year $(0 \cdot 4 / 1000 /$ year $)$.

Sixty three children ( 31 boys, 32 girls) had a history of epilepsy-that is, recurrent afebrile seizures-an incidence of $4 \cdot 3 / 1000$. Twenty two of these children had been free of seizures for two years before the 10 year follow up, leaving $41(2 \cdot 8 / 1000)$ with active epilepsy.

Of the 14278 in the cohort who had had no febrile convulsions, $53(3 \cdot 7 / 1000)$ developed epilepsy. Seventeen children had had febrile seizures at some time before their afebrile seizures. ${ }^{8}$ Eighteen children had had one or more episodes of afebrile status epilepticus.

\section{DISTRIBUTION OF SEIZURE TYPES}

The commonest seizure types were tonic-clonic and 
complex partial (table I). All but four of the children with complex partial seizures had attacks that were secondarily generalised at some time. All children who had infantile spasms subsequently developed a mixed seizure disorder. Only one child had classic absence seizures (petit mal). Seven children had atypical absence seizures, five of whom also had other types of seizure: one had infantile spasms first and the other four had "mixed" seizures.

\section{INTERVAL BETWEEN FIRST AND SECOND SEIZURE}

Sixty three $(75 \%)$ of the 84 children with seizures had recurrent seizures (epilepsy). The timing of recurrence was known for 55 . Twenty eight children had the second seizure within a month, 49 within a year, 51 within two years, and 54 within three years.

Seizures started after the age of 7 years in only 14 children (seven complex partial, five tonic-clonic, and two atypical absence) and six children had had a recurrence before age 10 years. Overall recurrence rates are therefore unlikely to have been distorted by short follow up in those presenting after 7 years of age.

\section{FACTORS ASSOCIATED WITH SEIZURE RECURRENCE}

Family history of epilepsy was known for 41 of the 44 children with idiopathic recurrent seizures (epilepsy) and 15 of 16 children with idiopathic single seizures. A greater proportion of children with recurrences (13/41,

TABLE IV-Children with clinical evidence of developmental delay or learning disability compared with other children with seizures. (Two children who died aged 10 months were excluded)

\begin{tabular}{lcrc}
\hline & $\begin{array}{c}\text { No (\%) with } \\
\text { developmental } \\
\text { delay (n=25) }\end{array}$ & $\begin{array}{c}\text { No (\%) with } \\
\text { normal } \\
\text { development } \\
(\mathrm{n}=57)\end{array}$ & $\begin{array}{c}\mathrm{p} \text { Value for } \\
\text { difference } \\
\text { between groups } \\
\left(\chi^{2} \text { value) }\right.\end{array}$ \\
\hline Symptomatic & $16(64)$ & $6(11)$ & $<0 \cdot 0001(22 \cdot 7)$ \\
Onset $<1$ year & $12(48)$ & $9(16)$ & $<0 \cdot 01(7 \cdot 8)$ \\
Status epilepticus & $8(32)$ & $9(16)$ & $\mathrm{NS}$ \\
Recurrence (epilepsy) & $24(96)$ & $39(68)$ & $<0.05(5 \cdot 96)$ \\
Remission after epilepsy & $5 / 20(20) \dagger$ & $17 / 39(44)$ & $\mathrm{NS}$ \\
\hline
\end{tabular}

†Excludes four children who died as remission was defined as being seizure free at 10 years of age.

TABLE V-Comparison between children with tonic-clonic and complex partial seizures

\begin{tabular}{|c|c|c|c|}
\hline . & $\begin{array}{l}\text { No }(\%) \text { with } \\
\text { tonic-clonic } \\
\text { seizures } \\
(\mathrm{n}=39)^{\star}\end{array}$ & $\begin{array}{l}\text { No }(\%) \text { with } \\
\text { complex partial } \\
\text { seizures } \\
(n=25)\end{array}$ & $\begin{array}{c}\mathrm{p} \text { Value for } \\
\text { difference } \\
\text { between groups } \\
\left(\chi^{2} \text { value }\right)\end{array}$ \\
\hline Male & $16(41)$ & $15(60)$ & NS \\
\hline $\begin{array}{l}\text { First degree relative with } \\
\text { idiopathic seizurest } \\
\text { Previous febrile }\end{array}$ & $8 / 30(27)$ & $6 / 21(29)$ & NS \\
\hline convulsion & $10(26)$ & $6(24)$ & NS \\
\hline $\begin{array}{l}\text { Symptomatic } \\
\text { Developmental delay or }\end{array}$ & $7(18)$ & $3(12)$ & NS \\
\hline learning disability & $9(23)$ & $3(12)$ & NS \\
\hline Status epilepticus & $2(5)$ & $3(12)$ & NS \\
\hline Recurrence (epilepsy) & $23(59)$ & $22(88)$ & $<0.05(4.8)$ \\
\hline Remission after epilepsy & $14 / 23(61)$ & $7 / 22(32)$ & NS \\
\hline
\end{tabular}

${ }^{\star}$ Excludes the three children with tonic-clonic seizures who died.

†Family history not available for two children with idiopathic tonic-clonic seizures and one with complex partial seizures.

TABLE VI-Details of disease in children with seizures who died in the first 10 years of life

\begin{tabular}{|c|c|c|c|c|}
\hline Seizure type & Age at first seizure & $\begin{array}{c}\text { Underlying or } \\
\text { predisposing cause }\end{array}$ & Age at death & Cause of death \\
\hline Mixed & 6 Weeks & Salmonella meningitis & 3 Years 4 months & $\begin{array}{l}\text { Collapse } \\
\text { hydrocephalus }\end{array}$ \\
\hline Mixed & 2 Months & Birth asphyxia & 1 Year 2 months & Gastroenteritis \\
\hline Mixed & 6 Months & $\begin{array}{l}\text { Leigh's } \\
\text { encephalopathy }\end{array}$ & 3 Years 4 months & Progression of disease \\
\hline $\begin{array}{l}\text { Tonic-clonic } \\
\text { Tonic-clonic }\end{array}$ & $\begin{array}{l}7 \text { Months } \\
10 \text { Months }\end{array}$ & $\begin{array}{l}\text { Encephalitis } \\
\text { Subarachnoid } \\
\text { haemorrhage }\end{array}$ & $\begin{array}{l}5 \text { Years } 11 \text { months } \\
10 \text { Months }\end{array}$ & $\begin{array}{l}\text { Bronchopneumonia } \\
\text { Subarachnoid } \\
\text { haemorrhage }\end{array}$ \\
\hline Tonic-clonic & 10 Months & $\begin{array}{l}\text { Pneumonia and } \\
\text { cerebral oedema }\end{array}$ & 10 Months & $\begin{array}{l}\text { Pneumonia and } \\
\text { cerebral oedema }\end{array}$ \\
\hline
\end{tabular}

$32 \%)$ than children with single afebrile seizures $(2 / 15$, $13 \%$ ) had a first degree relative with epilepsy, but this did not reach significance. Sex did not affect recurrence rate: $76 \%(22 / 29)$ of girls with idiopathic seizures had a recurrence compared with $71 \%(22 / 31)$ of boys.

All the children who had seizures other than tonicclonic and complex partial developed epilepsy. No significant increase was found in the proportion of children with recurrent seizures among those with onset in the first year of life (table II) or those with symptomatic seizures (table III). A greater proportion of children with developmental delay or learning disability (table IV) and complex partial seizures (table V) developed epilepsy compared with other children with seizures.

ONSET OF SEIZURES IN FIRST YEAR OF LIFE

Excluding the neonatal period, 23 children (13 boys, 10 girls) had their first seizure in the first year of life. Eleven children had tonic-clonic seizures, two complex partial seizures, and one myoclonic seizures; six children had a mixed seizure disorder and three children presented with infantile spasms but later developed a mixed seizure disorder.

Outcome depended on seizure type. The three children who presented with infantile spasms and the six with a mixed seizure disorder had a poor outcome. All had evidence of developmental delay, three of the children with mixed seizures died, and none of the six survivors were in remission at 10 years of age. Of the 11 children who presented with tonic-clonic seizures, three died (two immediately of the underlying cause). Of the remaining eight children with tonic-clonic seizures, only one showed evidence of developmental delay and seven had been free of seizures for two years by age 10

A greater proportion of children who had onset of seizure in the first year rather than later had symptomatic seizures and a greater proportion of the survivors showed evidence of developmental delay or learning disability, but there was no increase in the proportion who had status epilepticus, developed epilepsy, or went into remission (table II).

\section{DEATHS}

Six children died in the first 10 years of life $-7 \cdot 8 \%$ of the children with afebrile seizures (table VI). All deaths occurred in children with symptomatic seizures that started in the first year of life. Two children presented with seizures and died almost immediately; the others died after an interval. The deaths were due to the underlying disease rather than to the seizures.

\section{CHILDREN WITH SYMPTOMATIC SEIZURES}

In 24 of the 84 children ( $29 \%$ ) a likely cause for the epilepsy was evident. Thirteen children had acute cerebral damage (with seizures during the acute event in 10) and 11 had a predisposing clinical condition (table III). Table III compares the children with symptomatic seizures with those with idiopathic seizures. All the deaths were in symptomatic children, of whom a significantly greater proportion had onset of seizures in the first year and showed later developmental delay or learning disability. After excluding the children who died, there was no significant difference in the proportion who had status epilepticus or developed epilepsy in the two groups. A smaller proportion of children with symptomatic epilepsy were in remission at 10 years, but this was not significant.

CHILDREN WITH DEVELOPMENTAL DELAY OR LEARNING DISABILITY

A greater proportion of children with developmental delay or learning disability had symptomatic seizures, had onset of seizure in the first year, and developed 
epilepsy compared with children with normal development (table IV). Although fewer children with developmental delay were in remission at 10 years this did not reach significance.

CHILDREN WITH TONIC-CLONIC AND COMPLEX PARTIAL SEIZURES

The median age of onset of seizures was 2 years 2 months (range 5 weeks- 9 years 3 months) in the tonicclonic group and 4 years 8 months $(5$ months -8 years 5 months) in the complex partial group. Table $\mathrm{V}$ compares the two groups. A significantly greater proportion of the complex partial group developed epilepsy (recurrent seizures), even though the median age of onset was later. No significant differences existed between the groups in sex distribution, family history of epilepsy, proportion that had previous febrile convulsions, or in proportions that had symptomatic epilepsy, had developmental delay or learning disability, or that were in remission at age 10 years.

\section{Discussion}

The incidence of epilepsy in the first 10 years of life in our study was $4 \cdot 3 / 1000$. The rate of epilepsy in the national child development study, one of the two other large British cohort studies, was $4 \cdot 1 / 1000$ by 11 years. ${ }^{3}$ That study also found little difference in prevalence according to sex. Nelson and Ellenberg reported a rate of epilepsy of $5 / 1000$ by age 7 years among American children who had not had febrile seizures; in our study the equivalent rate was $3 \cdot 7 / 1000$ by age 10 . Most studies of relatively unselected populations report a prevalence of chronic epilepsy between 4 and $10 / 1000 .^{11}$

\section{SEIZURE RECURRENCE}

Reported rates of recurrence after a single fit vary between $27 \%$ and $82 \% .^{12}$ Chadwick's review ${ }^{13}$ drew attention to the national general practitioner study of epilepsy, ${ }^{14}$ which found a rate of recurrence of $78 \%$ at 3 years, including first seizures that were identified retrospectively. This rate is similar to ours, probably because the method was similar. In contrast the hospital based study by Hauser et al found a recurrence rate at 3 years of only $29 \% .{ }^{15}$ Variation may be due partly to population selection and partly to delay in referral after the first seizure-if some patients have a second seizure before they can be enrolled those that are enrolled are less likely to have a recurrence. Hospital based studies therefore usually give lower recurrence rates than community based studies.

We found that the rate of recurrence was increased in children with dëelopmental delay or learning disability and in children with complex partial seizures. These two results just attained statistical significance $(p<0.05)$. Because of the number of $\chi^{2}$ tests performed at least one of the two results may have been significant on a purely random basis. However, Berg and Shinnar reported similar findings in their meta-analysis of previous studies. ${ }^{16}$

\section{DISTRIBUTION OF SEIZURE TYPES}

In their general practice based study Goodridge and Shorvon ${ }^{17}{ }^{18}$ used the same classification as we did, and our results agree quite well even though the age range studied was different. The same proportion of electroencephalograms appeared normal in both studies. The proportions of children with mixed seizure disorder, simple partial seizures with secondary generalisation, and classic absence seizures were also similar in both studies. Ross et al found only one child with "petit mal" in the British 1958 cohort. Brief "blank spells" in childhood are probably brief complex partial seizures or atypical absence seizures (sometimes part of a mixed seizure disorder).

The clinical information available in our study (recorded in the 1970s) was not sufficiently specific for us to diagnose benign partial epilepsy.

\section{OUTCOME AFTER SEIZURES}

Chevrie and Aicardi studied outcome after seizures in the first year of life in 293 infants and reported a generally poor prognosis, outcome being worse in symptomatic than cryptogenic cases. ${ }^{19}{ }^{20}$ Cavazutti et al reported similar findings. ${ }^{21}$ We found that all the deaths occurred in children who had developed afebrile symptomatic seizures in the first year. We also found that children who had infantile spasms or a mixed seizure disorder in the first year were more likely to have persistent seizures whereas the outcome for children who presented with tonic-clonic seizures in the first year was relatively good.

A greater proportion of children with symptomatic seizures presented in the first year and showed evidence of developmental delay or learning disability. Many other studies have reported similar findings. We looked for "avoidable" epilepsy in this group, but there were only five cases in which the seizures might have been prevented (two head injuries, one birth asphyxia, one child put in a hot bath during a febrile convulsion, one postoperative electrolyte imbalance).

\section{TONIC-CLONIC VERSUS COMPLEX PARTIAL SEIZURES}

Prolonged febrile seizures in childhood have been suggested to cause mesial temporal sclerosis and thus lead to later complex partial seizures. ${ }^{22}{ }^{23} \mathrm{We}$ found no difference between the tonic-clonic and complex partial groups in the proportion with a history of febrile convulsions. This supports Rocca et al's opinion that when febrile seizures precede afebrile seizures there is a usually pre-existing liability for the brain to convulse. ${ }^{24}$ They suggested that there is a genetic predisposition in the case of generalised seizures and a pre-existing brain lesion in the case of complex partial seizures, but we found no greater proportion with a positive family history in the tonic-clonic group nor an increased proportion of symptomatic seizures in the complex partial group. In this part of the study our numbers were small and our conclusions are tentative.

We found that a greater proportion of children with complex partial seizures had recurrences, as reported by others. ${ }^{17} 26$ Although a larger percentage of children in the tonic-clonic group had a remission this was not significant. Annegers et al found that remission was more likely in children with generalised onset rather than complex partial seizures.

\section{DEATHS}

Our findings are similar to those of Chevrie and Aicardi, who studied children with onset of seizures in the first year of life and found that $19 \%$ of children with symptomatic seizures died compared with $4 \%$ with cryptogenic seizures. ${ }^{19}$ In contrast Sillanpaa found that none of those who developed seizures in the first year of life died immediately. ${ }^{28}$

CONCLUSIONS

Although there is understandable concern when epilepsy is diagnosed it should be remembered that it is mainly children with symptomatic seizures who have a poor outcome. Such children were the minority in our study and the children with idiopathic seizures did much better.

Professor Neville Butler created the child health and education study out of the original birth survey. The study was funded by the Medical Research Council, the Department of Health and Social Security, and the Gertrude H Sergievsky 
Center of Columbia University, New York. We thank the midwives, health visitors, general practitioners, medical records officers, and clinicians who provided essential information and also the children and their parents.

1 Cooper JE. Epilepsy in a longitudinal survey of 5000 children. BMf 1965;i $1020-2$

2 van den Berg BJ, Yerushalmy J. Studies on convulsive disorders in young children. I. Incidence of febrile and nonfebrile convulsions by age and other factors. Pediatr Res 1969;3:298-304

3 Ross EM, Peckham CS, West PB, Butler NR. Epilepsy in childhood: findings from the national child development study. BMf 1980;280:207-10

4 Ellenberg JH, Hirtz DG, Nelson KB. Age at onset of seizures in young children. Ann Neurol 1984;15:127-34

5 Chamberlain R, Chamberlain G, Howlett B, Claireaux A. British births 1970. Vol 1. The first week of life. London: William Heinemann, 1978.

6 Verity CM, Butler NR, Golding J. Febrile convulsions in a national cohor followed up from birth. I. Prevalence and recurrence in the first five years of life. $B M 7$ 1985;290:1307-10

7 Verity CM, Butler NR, Golding J. Febrile convulsions in a national cohort followed up from birth. II. Medical history and intellectual ability at 5 years of age. BMF 1985;290:1311-5.

8 Verity $\mathrm{CM}$, Golding J. Risk of epilepsy after febrile convulsions: a national cohort study. BMF 1991;303:1373-6.

9 The Commission on Classification and Terminology of the International League Against Epilepsy. Proposal for revised clinical and electroencephalographic classification of epileptic seizures. Epilepsia 1981;22:489-501.

10 Nelson KB, Ellenberg JH. Predictors of epilepsy in children who have experienced febrile seizures. N Engl f Med 1976;295:1029-33.

11 Sander JWAS, Shorvon SD. Incidence and prevalence studies in epilepsy and their methodological problems: a review. I Neurol Neurosurg Psychiatr 1987;50:829-39.

12 Shorvon SD. The temporal aspects of prognosis in epilepsy. $f$ Neurol Neurosurg Psychiatry 1984;47:1 157-65.

13 Chadwick D. Epilepsy after first seizures: risks and implications. 7 Neurol Neurosurg Psychiatry 1991:54:385-7.
14 Hart Y.M, Sander JWAS, Johnson AL, Shorvon SD, for the NGPSE. National general practice study of epilepsy: recurrence after a first seizure. Lancel 1990;336:1271-4.

15 Hauser WA, Rich SS, Annegers JF, Anderson VE. Seizure recurrence after a first unprovoked seizure: an extended follow-up. Neurology 1990;40: $1163-70$

16 Berg AT, Shinnar S. The risk of seizure recurrence following a first unprovoked seizure: a quantitative review. Neurology 1991;41:965-72.

7 Goodridge DMG Shorvon SD. Epileptic scizures in a population of 6000. Deme DMG Shory SD. Epile Demography, diagnosis,

18 Goodridge DMG, Shorvon SD. Epileptic seizures in a population of 6000 . II Treatment and prognosis. BMF 1983;287:645-7.

19 Chevrie JJ, Aicardi J. Convulsive disorders in the first year of life: neurological and mental outcome and mortality. Epilepsia 1978;19:67-74.

Chevrie JJ, Aircardi J. Convulsive disorders in the first year of life persistence of epileptic seizures. Epilepsia 1979;20:643-8.

21 Cavazutti GB, Ferrari P, Lalla $M$. Follow-up study of 482 cases with convulsive disorders in the first year of life. Dev Med Child Neurol 1984;26:425-37.

22 Falconer MA, Serafetinides EA, Corsellis JAN. Etiology and pathogenesis of temporal lobe epilepsy. Arch Neurol 1964;10:233-48.

23 Taylor DC, Ounsted C. Biological mechanisms influencing the outcome of seizures in response to fever. Epilepsia 1971;13:33-45.

A, Sharbrough FW, Hauser WA factors for generalized tonic-clonic seizures: a population-based case-control Roca WA, Sharbroug FW, Hauser WA, Annegers J15-22.

choenberg BS. Risk factors for complex partial seizures: a population-based case-control study. Ann Neurol 1987;21:22-31.

26 Annegers JF, Shirts SB, Hauser WA, Kurland LT. Risk of recurrence after an initial unprovoked seizure. Epilepsia 1986;27:43-50.

27 Annegers JF, Hauser WA, Elveback LR. Remission of seizures and relapse in patients with epilepsy. Epilepsia 1979;20:729-37.

28 Sillanpaa M. Medico-social prognosis of children with epilepsy. Acta Paediatr Scand 1973;Suppl 273:1-104

(Accepted 20 August 1992)

\title{
Cost implications of the British Pacing and Electrophysiology Group's recommendations for pacing
}

\author{
M A de Belder, N J Linker, Sue Jones, A J Camm, D E Ward
}

Abstract

Objective-To compare present pacing practice with the recommendations recently published by the British Pacing and Electrophysiology Group and to assess the increase in annual budget required to implement these recommendations in a regional cardiothoracic unit.

Design-Retrospective analysis of pacemaker implantation for 1991 with calculation of the costs required to implement the group's recommendations based on average 1991 costs of the types of pacing generators and electrode leads used.

Setting-Regional cardiothoracic unit for South West Thames Health Authority.

Patients-433 consecutive patients receiving permanent pacemaker generators: $76(18 \%)$ with sinus node disease; $270(62 \%)$ with atrioventricular block; $25(6 \%)$ with both sinus node disease and atrioventricular block; $59(14 \%)$ with chronic atrial fibrillation and atrioventricular block; and $3(1 \%)$ with carotid sinus or malignant vasovagal syndromes.

Results-Only $102(24 \%)$ patients received pacemaker generators recommended by the British Pacing and Electrophysiology Group; however, 355 $(82 \%)$ patients were older than 65 years, and 264 $(61 \%)$ were aged 75 or over. The cost of hardware for pacing was $£ 462885$. Using generators as recommended would have cost $£ 810525$ for "optimal" systems (an increase of $75 \%$ ) and $£ 710750$ for "alternative" systems (an increase of 54\%). These increases would have been considerably reduced by limiting the use of sophisticated pacing to younger patients (aged under 75). Further savings could be made by using the least expensive pacing models available.

Conclusions-Implementing these recommenda- tions should reduce morbidity related to bradyarrhythmia but will lead to major increases in pacing costs. Age and patients' expected activity may be used to select simple pacing systems and thus to contain cost. More research is needed to determine which patient groups will benefit most from complex pacing systems.

\section{Introduction}

The British Pacing and Electrophysiology Group has recently published its recommendations for pacemaker prescription for symptomatic bradycardia. ${ }^{1}$ Its report discussed three pacing "policies": right ventricular demand (VVI) pacing for everyone (which was deemed inappropriate); the routine use of the most $\tilde{N}$ sophisticated system appropriate for the patients' I needs (acceptable but costly); and careful prescription along the recommendations of the report. The working party acknowledged that a radical change in practice would be needed in some pacing centres. Additional funding would also be required for more widespread use of dual chamber and rate responsive pacing systems and their follow up. The extent of the additional funding required is unknown but depends on the prevalence of the different electrocardiographic diagnostic groups (as used by the British Pacing and Electrophysiology Group) in the general population. Table I shows the recommended systems.

Many centres, ours included, at present use far more single electrode ventricular (VVI) pacing systems than is suggested by these recommendations. Although the British Pacing and Electrophysiology Group accepted that these systems might suffice for atrioventricular block in the face of terminal disease or conditions that reduce mobility (for example, previous hemiplegia), most centres use these modes predominantly in elderly 